\title{
A Study of Predictive Factors in the Outcome of Necrotizing Fasciitis in Patients of Sepsis
}

\author{
Vangari Ravi ${ }^{\oplus 1}$, Mohammad Jahangir ${ }^{\oplus 2}$ \\ ${ }^{1}$ Assistant Professor, General Surgery, Osmania General Hospital, Hyderabad, Telangana, India, ${ }^{2}$ Final Year Post Graduate, Department of Surgery, Osmania Medical \\ College and Hospital, Hyderabad, Telangana, India.
}

\section{Abstract}

Background: Necrotizing fasciitis is an infection occurring in the deep fascial layers. It is a progressive infection. The diagnosis of necrotizing fasciitis is usually clinical and is important to find it early as it is a fast spreading infection. Necrotizing fasciitis occurs as a result of necrosis of skin and subcutaneous layer. The aim of the study is to assess factors which will help in clinching the diagnosis of Necrotizing Fasciitis and to identify factors responsible for morbidity and mortality. The study was hospital based observational study conducted for 2 years from May 2017- June 2019 on 30 patients with necrotizing fasciitis at Department of general surgery, Osmania General Hospital. Subjects and Methods: Clinical and anatomical findings rendered initial diagnosis. The patient's details have been noted. Detailed patient interview on history and other comorbid conditions was conducted. Bacteriological culture is done. Following initial debridement, the wound was inspected regularly and subsequent debridement was done periodically whenever necessary. Results: Majority of the patients were males, $80 \%$ and the rest $20 \%$ were females. In $56.66 \%$ of the patients the site of NF was perineum and in the rest $43.33 \%$ of the patients it was in the extremities. The type of bacterial culture done was polyculture in majority $90 \%$ of the patients and monoculture was done in the rest $10 \%$ of the patients. $30 \%$ of the patients tested positive for NF and rest $70 \%$ were found to be negative with NF. The mortality rate was $30 \%$ and morbidity rate was $10 \%$. Conclusion: Effective and vigorous surgical debridement, often in multiple sessions, supplemented by adequate antibiotics and supportive treatment, is the key to a successful result with necrotizing fasciitis.

Keywords: Necrotizing Fasciitis, Mortality, Morbidity, Perineum, Extremities

Corresponding Author: Mohammad Jahangir, Final Year Post Graduate, Department of Surgery, Osmania Medical College and Hospital, Hyderabad, Telangana, India.

E-mail: jahangirmohammad917@gmail.com

Received: 20 December 2019

Revised: 29 January 2020

Accepted: 05 February 2020

Published: 27 May 2020

\section{Introduction}

Necrotizing fasciitis (NF) is a rare medical and surgical emergency. It is a rapidly progressing severe disorder of soft tissue with significant skin necrosis, subcutaneous tissues, and superficial fascia or muscles. Necrotizing fasciitis is an infection occurring in the deep fascial layers. It is a progressive infection. The diagnosis of necrotizing fasciitis is usually clinical and is important to find it early as it is a fast spreading infection. Necrotizing fasciitis occurs as a result of necrosis of skin and subcutaneous layer. In some cases, there will be necrosis of underlying muscles causing necrotizing myositis. Necrotizing fasciitis often spreads by direct spread. In severe cases, the microorganisms can spread via blood vessel and lymphatics resulting in sepsis and shock.

Bisno et al. ${ }^{[1]}$ described it as a deep-seated tissue infection and superficial fascia that leads to progressive degradation of the subcutaneous tissue. There are no pathognomonic signs indicating the presence of NF at the early stages. There are wide range of symptoms and indications of NF like vesicles, edema, bullae, cellulitis, erythema, crepitus, and fever. Patients are seldom diagnosed with cellulitis before accelerated decomposition is detected. The complications are typically severe sepsis and death. Complications include severe sepsis and mortality. Necrotizing fasciitis is more common in the elderly age group $>50$ years of age, but it can occur in virtually every age group including infants, and healthy adults can also be affected. Due to the increased incidence of diabetes and other immunocompromised conditions, the prevalence of necrotizing fasciitis has dramatically increased.

\section{Subjects and Methods}

\section{Place of Study}


This study was conducted at Department Of General Surgery, Osmania General Hospital, Hyderabad. Telangana.

\section{Type of Study}

This was hospital based observational study.

\section{Sample Collection}

Sample Size: 30

\section{Sampling Methods}

Consecutive patients.

\section{Inclusion Criteria}

All patients admitted with Necrotizing Fasciitis were included in the study.

\section{Exclusion Criteria}

Patients with Non-Necrotizing soft tissue infections were excluded from study (e.g. Cellulitis, abscess).

\section{Statistical Analysis}

Data were presented in the form of statistical tables and charts. SPSS software version 20 was used for statistical analysis.

\section{Ethical Approval}

Approval was taken from the Institutional Ethics Committee prior to commencement of the study.

Patients presenting with features of necrotizing fasciitis were admitted in the general surgery ward of the Osmania medical college. Clinical and anatomical findings rendered initial diagnosis. The patient's details have been noted. Detailed patient interview on history and other comorbid conditions was conducted. bacteriological culture is done. Following initial debridement, the wound was inspected regularly and subsequent debridement were done periodically whenever necessary. And dressing was done using povidone iodine and saline gauze. After the wound is fit, patient undergone split skin graft surgery for raw area.

\section{Results}

Majority of the patients belonged to the age group of $40-49$ years amounting to $36.66 \%$ followed by more the 60 years age group constituting $23.33 \%$ followed by $50-59$ years age range with $20 \%$ and the least belonging to the $20-29$ years age group with $6.66 \%$. Majority of the patients were male amounting to $80 \%$ and the rest $20 \%$ were females. In $56.66 \%$ of the patients the site of NF was perineum and in the rest $43.33 \%$ of the patients it was in the extremities.

In majority of the patient's line of treatment done in around $66.66 \%$ was debridement, followed by SSG in $23.33 \%$ then equally followed by Amputation, permanent colostomy and testis placement constituting $3.33 \%$ each.
Table 1: Distribution of patients across age groups, gender, site of NF and frequency

\begin{tabular}{lll}
\hline Age in years & Frequency & Percent \\
\hline $20-29$ & 2 & $6.66 \%$ \\
$30-39$ & 4 & $13.33 \%$ \\
$40-49$ & 11 & $36.66 \%$ \\
$50-59$ & 6 & $20.00 \%$ \\
$>60$ & 7 & $23.33 \%$ \\
Gender & & \\
Females & 6 & $20.00 \%$ \\
Males & 24 & $80.00 \%$ \\
Site & & \\
\hline Perineum & 17 & $56.66 \%$ \\
\hline Extremities & 13 & $43.33 \%$ \\
\hline
\end{tabular}

Table 2: Treatment for necrotizing fasciitis

\begin{tabular}{lll}
\hline Treatment & Frequency & Percent \\
Debridement & 20 & $66.66 \%$ \\
\hline Amputation & 1 & $3.33 \%$ \\
SSG & 7 & $23.33 \%$ \\
Permanent & 1 & $3.33 \%$ \\
colostomy & & $3.33 \%$ \\
Testis Placement & 1 & $100.00 \%$ \\
Total & 30 & \\
\hline
\end{tabular}

Table 3: Bacteriology - Gram positive and gram negative bacteria

\begin{tabular}{lll}
\hline $\begin{array}{l}\text { Bacteriology } \\
\text { (Gram Positive) }\end{array}$ & Frequency & Percent \\
\hline $\begin{array}{l}\text { Staphylococcus } \\
\text { Streptococcus }\end{array}$ & 2 & $6.66 \%$ \\
\hline $\begin{array}{l}\text { Group A strepto- } \\
\text { cocci }\end{array}$ & 7 & $3.33 \%$ \\
\hline $\begin{array}{l}\text { Coagulase negative } \\
\text { Satphylococcus }\end{array}$ & 1 & $23.33 \%$ \\
\hline $\begin{array}{l}\text { Bacteriology } \\
\text { (Gram Negative) }\end{array}$ & & $3.33 \%$ \\
\hline $\begin{array}{l}\text { E.coli } \\
\text { Proteus }\end{array}$ & 5 & \\
\hline $\begin{array}{l}\text { Citrobacter } \\
\text { Klebsiella }\end{array}$ & 2 & $16.66 \%$ \\
\hline $\begin{array}{l}\text { Non fermenting } \\
\text { bacilli }\end{array}$ & 1 & $3.33 \%$ \\
\hline Enterococci & 1 & $6.66 \%$ \\
\hline & & $10.00 \%$ \\
\hline
\end{tabular}


The gram-positive bacteria found in the patients were staphylococcus, streptococcus, group A streptococci and coagulase negative staphylococcus. The gram-negative bacteria found in the patients were E. coli, Proteus, Citrobacter, Klebsiella, Non fermenting bacilli, Enterococci.

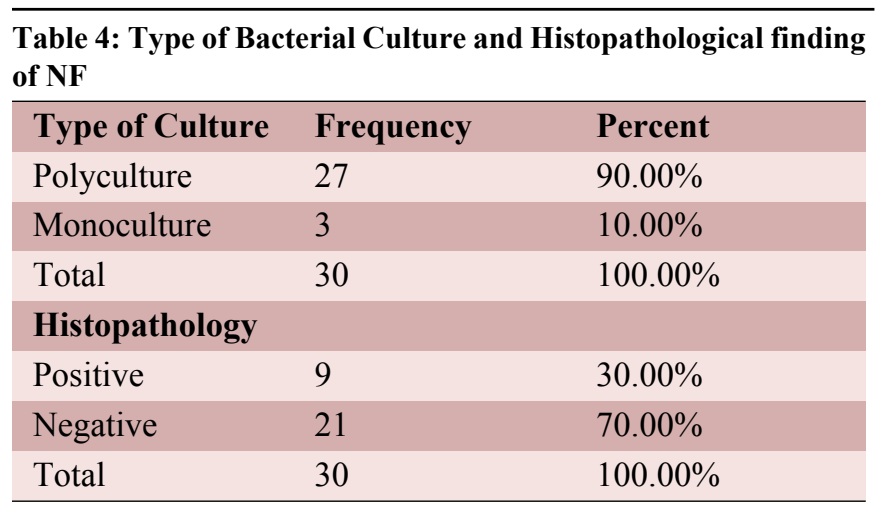

The type of bacterial culture done was polyculture in majority $90 \%$ of the patients and monoculture was done in the rest $10 \%$ of the patients. $30 \%$ of the patients tested positive for NF and rest $70 \%$ were found to be negative with NF

Table 5: Outcome of the study

\begin{tabular}{lll}
\hline Outcome & Frequency & Percent \\
Died & 9 & $30.00 \%$ \\
Survived & 21 & $70.00 \%$ \\
Total & 30 & $100.00 \%$ \\
\hline
\end{tabular}

Out of 30 patients 9 patients constituting $30 \%$ died and the rest 21 patients constituting $70 \%$ survived.

\section{Discussion}

Necrotizing fasciitis, although not common, can cause notable rates of morbidity and mortality. Necrotizing fasciitis has an occurrence of 1,000 cases per year and a worldwide frequency of 0.040 cases per 1,000 person-years. ${ }^{[2]}$ It is important to have a high index of suspicion and increase awareness in view of the paucity of specific cutaneous findings early in the course of the disease. Prompt diagnosis and early operative debridement with adequate antibiotics are vital. Today, necrotizing fasciitis is an uncommon disease process yet one that must be recognized and dealt with rapidly. If not treated promptly and aggressively, the virulent and toxin-producing bacteria, most commonly group Streptococcus pyogenes, will cause severe systemic toxicity which may lead to death. Common risk factors include diabetes mellitus, immunocompromised states, peripheral vascular disease, cardiac disease, obesity, intravenous drug use, alcohol use, malnutrition, smoking as well as corticosteroid use and chronic use of non-steroidal anti-inflammatory drugs. ${ }^{[3-5]}$ Despite the large number of predisposing factors that have been identified, half of all cases of necrotizing fasciitis occur in healthy individuals. Early surgical intervention preventing a delay of more than twentyfour hours prevented an adverse outcome.

All our patients were managed in ICU with aggressive fluid resuscitation and early and prompt debridement in all patients. They were treated with 4th generation cephalosporins, aminoglycosides, metronidazole and multiple debridement's were done and frequency of dressing was twice daily.

Majority of the patients belonged to the age group of $40-49$ years amounting to $36.66 \%$ followed by more the 60 years age group constituting $23.33 \%$ followed by $50-59$ years age range with $20 \%$ and the least belonging to the $20-29$ years age group with $6.66 \%$. Majority of the patients were male amounting to $80 \%$ and the rest $20 \%$ were females. In $56.66 \%$ of the patients the site of NF was perineum and in the rest $43.33 \%$ of the patients it was in the extremities. The grampositive bacteria found in the patients were staphylococcus, streptococcus, group A streptococci and coagulase negative staphylococcus. The gram-negative bacteria found in the patients were E. coli, Proteus, Citrobacter, Klebsiella, Non fermenting bacilli, Enterococci. The type of bacterial culture done was polyculture in majority $90 \%$ of the patients and monoculture was done in the rest $10 \%$ of the patients. $30 \%$ of the patients tested positive for NF and rest $70 \%$ were found to be negative with NF.

Mortality rate was $30 \%$ and deaths were due to sepsis, acute respiratory distress, Multiple organ syndrome, Infective dysfunction syndrome and metabolic encephalopathy. In a study by Czymek et al., the mortality was significantly higher among females $(50 \% \mathrm{~F}$ vs. $7.7 \% \mathrm{M}),{ }^{[6]}$ but in larger clinical studies, female sex did not seem to affect mortality. ${ }^{[7]}$

Morbidity was $10 \%$ involving amputations, Disarticulations, Colostomy, Placement of both testes in anteromedial sides of thigh, Bilateral orchidectomy, split skin grafting's leading to contractions. In a clinical study performed by Anaya et al., the lower extremities were mostly affected $(57.8 \%)$, ${ }^{[8]}$ accompanied by the abdomen and perineum. Goh et al. [9] calculated the prevalence of diabetes mellitus in patients with $\mathrm{NF}$ at $44.5 \%$, It is unclear that diabetes mellitus impacts the mortality rate.

\section{Conclusion}

Necrotizing fasciitis does not need any predisposing conditions to be prone to, it can happen to anyone young, old, child, any race, any size, healthy or not. The nature of early NF and its non-specific clinical signs can considerably delay the diagnosis. Delay in the diagnosis by a matter of hours significantly increases mortality. Operative treatment delayed 
by few hours shown increased mortality. Low serum sodium and histopathological evidence are the hard signs to clinch the diagnosis. Any two of the following factors at presentation indicate grave prognosis: Shock at presentation, Delay of $24 \mathrm{hrs}$. before hospitalization, Anemia, hypoproteinemia and Increased blood sugar levels. Effective and vigorous surgical debridement, often in multiple sessions, supplemented by adequate antibiotics and supportive treatment, is the key to a successful result with necrotizing fasciitis.

\section{References}

1. Bisno AL, Chambers HF. Practice guidelines for the diagnosis and management of skin and soft tissue infections: 2014 update by the Infectious Diseases Society of America. Clin Infect Dis. 2014;15:10-52.

2. Bilton BD, Zibari GB, Mcmillan RW. Aggressive surgical management of necrotizing fasciitis serves to decrease mortality: a retrospective study. Am Surg. 1998;64:397-401.

3. Ray-Zack MD, Hernandez MC, Younis M, Hoch WB, Soukup DS, Haddad NN, et al. Validation of the American Association for the Surgery of Trauma emergency general surgery grade for skin and soft tissue infection. J Trauma Acute Care Surg. 2018;84(6):939-945. Available from: https://dx.doi.org/10.1097/ta.0000000000001860. doi:10.1097/ta.0000000000001860.

4. Tominaga GT, Staudenmayer KL, Shafi S. The American Association for the Surgery of Trauma grading scale for 16 emergency general surgery conditions: Disease-specific criteria characterizing anatomic severity grading. J Trauma Acute Care Surg. 2016;81:593-97.
5. Sartelli M, Malangoni MA, May AK. World Society of Emergency Surgery (WSES) guidelines for management of skin and soft tissue infections. World J Emerg Surg. 2014;9:57-62.

6. Rhodes A, Evans LE, Alhazzani W. Surviving Sepsis Campaign: International Guidelines for Management of Sepsis and Septic Shock: 2016. Intensive Care Med. 2017;43:304-313.

7. Bucca K, Spencer R, Orford N, Cattigan C, Athan E, McDonald A. Early diagnosis and treatment of necrotizing fasciitis can improve survival: an observational intensive care unit cohort study. ANZ J Surg. 2013;83(5):365-370. Available from: https://dx.doi.org/10.1111/j.1445-2197.2012.06251. x. doi:10.1111/j.1445-2197.2012.06251.x.

8. Anaya DA, Mcmahon K, Nathens AB, Sullivan SR, Foy H, Bulger E. Predictors of mortality and limb loss in necrotizing soft tissue infections. Arch Surg. 2005;140:151-157.

9. Goh T, Goh LG, Ang CH, Wong CH. Early diagnosis of necrotizing fasciitis. Br J Surg. 2014;101(1):e119-e125. Available from: https://dx.doi.org/10.1002/bjs.9371. doi:10.1002/bjs.9371.

Copyright: (C) the author(s), 2020. It is an open-access article distributed under the terms of the Creative Commons Attribution License (CC BY 4.0), which permits authors to retain ownership of the copyright for their content, and allow anyone to download, reuse, reprint, modify, distribute and/or copy the content as long as the original authors and source are cited.

How to cite this article: Ravi V, Jahangir M. A Study of Predictive Factors in the Outcome of Necrotizing Fasciitis in Patients of Sepsis. Acad. J Surg. 2020;3(1):93-96.

DOI: dx.doi.org/10.47008/ajs/2020.3.1.20

Source of Support: Nil, Conflict of Interest: None declared. 